lithotrite, and in the course of a few minntes broke up the stone, which was composed of oxalate of lime, into small fragments. Chloroform was now administered to the patient by Mr. T. G. Alderton, in preference to ether, on account of the brouchitis. Mr. Teevan then passed a rectangular catheter staff, and handed it to Mr. Alfred Cooper to hold. An incision was made into the perineal urethra in the median line, and the stricture completely divided. The left forefinger was gently insinuated into the bladder, a slender urethral forceps introduced, and the fragments of stone extracted one by one. The bladder was then washed out, and a piece of lint dipped in carbolic acid inserted in the wound. At 8 P.M., when Mr. Brown, the house-surgeon, visited the patient, he found him comfortable; pulse 88 ; temperature $99^{\circ}$. The piece of lint was removed, in order to facilitate the patient's passing water, which he did after exerting a considerable effort. Half an hour later a severe rigor took place. Temperature $100^{\circ} 6^{\circ}$; pulse 85 . Ten grains of quinine were at once administered.

20th. - Has slept pretty well, and is free from pain. Pulse 90 ; temperature $100^{\circ}$.

23rd. - Complains of pain across the chest; respiration rather laboured; coarse, loud râles at base ; tongue coated and somewhat dry. Temperature $100 \cdot 8^{\circ}$; pulse 92, soft, jerky, and intermittent.

24th.-Has slept well, and takes food freely; is taking brandy; respiration laboured; tongue coated, but moist. Temperature $99.4^{\circ}$; pulse 64 , intermittent, soft, and irregular.-10 P.M. : Pulse fuller and stronger; slight muttering delirium.

26th.-Much better; passes urine equally by the wound and the penis.

April 1st.-Much stronger; wound fast closing.

7th.-Gets up for a few hours each day; most of the urine comes by the penis. No. 18 soft olivary catheter was passed into the bladder with ease.

15th.-Patient much improved in health; wound nearly healed; all urine comes by the penis. No. 20 olivary catheter passed.

17th.-Left hospital to-day.

25th.-Wound quite closed. Takes a walk every day.

June lst.-Patient still improving; is fit for any light work. Since the operation the bladder has regained much tone, and whereas formerly he could make but little water without the catheter, he now uses it but once a day in order to completely empty his bladder. The urine still contains a considerable amount of albumen.

Mr. Teevan remarked that the case was full of interest, and probably unique. Lithotrity at one sitting had been performed by Bigelow, perineal lithotrity by Dolbeau, Gouley, and Henry Lee, and lithotomy had occasionally been executed some days or weeks after lithotrity, as a matter of necessity not previously contemplated; but the special combination which he had effected in the present instance of designedly reducing the entire stone to small fragments at one sitting "per penem," and then im. mediately extracting them through a median perineal incision, was, he believed, quite novel. The objections to perineal lithotrity were the time required to perform the operation, and the risk encountered in manipulating a lithotrite in a bladder which had been completely emptied of urine by the median incision in the perineum through which the instrument was introduced. Median lithotomy per se was only applicable for the removal of very small stones, such, indeed, as the fragments of a calculus which had been completely crushed. No surgeon would, he thought, have performed lithotrity pure and simple in the present instance, complicated as it was by stricture of the urethra and atony of the bladder. Many operators would have done lateral lithotomy, and not a few would probably have declined all interference. As, however, the man was suffering much pain, and wished to be relieved, it would have been cruel to have left him to die unrelieved. But what operation should he undertake? Lithotrity by itself was out of the question, and lateral lithotomy would, in all probability, have been followed by a fatal issue, considering the complicated nature of the case. It occurred to Mr. Teevan that if a lithotomy could be reduced to a mere external urethrotomy, the patient's chances of recovery would be greatly increased, for statistics went to show that lithotomy in adults was ten times more fatal than external urethrotomy. Now, this desirable result could only be effected by employing lithotrity to break up the stone into fragments small enough to be extracted through a perineal incision without cutting or lacerating the neck of the bladder. It was, moreover, necessary that, whatever the operation proposed, the stone should be removed at one sitting, for if the fragments were not extracted for some days after they had been formed, it was clear that the patient's cystitis would be greatly aggravated, even to the destruction of life, as the bladder would be unable to eject the pieces. He had accordingly applied the combined operations as described with the happiest result, and he considered there vere many cases that would be best dealt with by such combination. One great advantage offered by the median incision in the present case was that it not only offered a free vent for the extraction of the fragments and the escape of any débris that might be left, but that it permitted the stricture, which had caused the atony of the bladder, to be divided. It was also to be remarked that the patient did not wet his bed after the operation, but had, on the contrary, to exercise a considerable effort to enable his weakened bladder to overcome the power of the sphincter.

\section{NEWPORT (MON.) INFIRMARY.}

PUNCTURED WOUND OF THE ABDOMEN, WITH PROTRUSION OF A LARGE AMOUNT OF SMALC INTESTINE, FOLLOWED BY TRAUMATIC DELIRIUM AND ERYSIPELAS ; RECOVERY. (Under the care of Dr. DAVIEs.)

Fon the following notes we are indebted to Mr. O. E. Bulwer Marsh, hotise-surgeon.

M. B_, a married man aged twenty-four years, labourer at the docks, was admitted at 12.30 on the morning of the 9 th of March. He had been stabbed in the abdomen with a clasp-knife by one of his comrades. The wound had been inflicted about two hours before.

Ou admission a large mass of small intestine and mesentery protruded from a wound in the left side of the abdomen, midway between the last rib and the crest of the ilium, and on a line with the umbilicus. The parts were so intensely tender and painful that the patient could not bear an examination withont chloroform, which he took well. It was then found that the wound was vertical and about an inch long, and through it protruded four coils of small intestine attached to the mesentery, each coil being about eight inches long. The intestine itself was not injured, but it was a good deal congested, and so tightly constricted at the opening that it was found impossible to return it into the abdominal cavity. The wound was therefore enlarged with a director and blunt-ended bistoury to about two inches and a half long, and the protruded mass was then easily reduced. The wound was brought together by two harelip pins, which were passed through the whole thickness of the abdominal wall, and between these two interrupted horsehair sutures were put in. A thick pad of lint dipped in tincture of benzoin was put over the wound, a broad bandage applied, and the patient put to bed and ordered one grain of opium every three hours. The pulse remained good after the operation. At 9 A.M. the pulse was 99 and the temperature $101^{\circ}$. The face was very flushed. He vomited once soon after he was put to bed, but otherwise he had passed a tolerably good night. The pupils were contracted, but acted. $\mathrm{He}$ was very drowsy. The abdomen was not swelled or tender, except just over the wounded part. Ordered ice and milk; the opium to be continued every four hours. The wife stated he had been a very heavy drinker lately, having seldom been quite sober of an evening since Christmas, but otherwise he had always been a healthy man. -9 P.M.: Temperature $101 \cdot 4^{\circ}$; pulse 100 , full and bounding. Tongue very white, but moist. He had vomited five times during the day. The ice and milk continued. Pupils still contracted. Abdomen only tender just over the area of the protruded intestine. No tympanites. The opium now given every six hours.

March 10th.-9 A.I.: Temperature $103^{\circ}$; pulse 102. Passed a quiet night. Tongue still thickly coated and rather tremulous. Has not vomited since yesterday evening. Opium still continued. Drowsiness and contracted pupils still remaining. Abdomen a little swelled, and there is slight tenderness on pressure on left side. Dressings not disturbed. Bowels have not acted since admission. Taking milk and ice in very small quantities. Urine, specific gravity 1010, acid and decidedly albuminous. - 9 P.M.: Pulse 128, full and bounding; temperature $104^{\circ}$. Abdomen rather tympanitic, 
and tenderness somewhat increased on left side. No vomiting. Tongue coated and rather dry and tremulous. No action of bowels. Perspiring rather profusely. Still seems very drowsy from the opium, which is continued at intervals of six hours.

11th. -9 A.M.: Pulse 128 ; temperature $104 \cdot 2^{\circ}$. Abdomen more tympanitic and tender than last night; tenderness a great deal more marked on left side. No vomiting or action of bowels. Still sweating profusely. Passed a pretty good night, but talked a good deal in his sleep. Dressings not removed.-9 P.M.: Pulse 120 and softer; temperature $103.4^{\circ}$. Abdomen somewhat more tender, but tympanites not sensibly increased. No vomiting during the day. Complains of extreme thirst, and he is still sweating profusely. Tongue thickly coated and dry. Was ordered an enema of soap and water, with two ounces of castor oil, after which the bowels acted once and he felt easier.

12th.-9 A.M.: Pulse 112 and better in tone; temperature $1032^{\circ}$. Tongue still furred, and skin perspiring. Abdomen not so tender as yesterday. No vomiting. Bowels have not acted since last night. Did not pass such a good night. Dressings not removed. The opium still continued.-9 P.M.: The soap-and-water and castor-oil enema repeated, after which the bowels were moved slightly once. Temperature $103 \cdot 6^{\circ}$; pulse 120 . Before the enema he complained of crampy pains in abdomen, which were easier afterwards.

13th.-Pulse 120 ; temperature $1034^{\circ}$. Tongue very tremulous, and covered with a thick creamy fur. Passed a restless night, and almost sleepless. Constantly trying to get out of bed, and the marked delirium, which came on rather suddenly, is very characteristic. Sweating profusely, and at times very violent. The bowels have not acted since the motion after the last enema. Abdomen not so tender, but round the pad on the left side there is a slight inflammatory blush. On account of the violent delirium it was not thought desirable to remove the dressing. Two nurses are kept constantly with him. The opium left off, and twenty grains of chloral, with twenty grains of bromide of potassium, to be given every two hours.-9 P.M.: Has been extremely restless and talkative all day, constantly trying to get out of bed, but has been restrained by the porter and two nurses. Perspiring profusely ; tongue very foul and tremulous ; and the breath fetid. The abdomen not more tender or tympanitic; no vomiting. The erysipelatous blush has extended a good deal ; dressings not touched. Ordered two ounces of compound senna mixture at 3 P.M., which did not act; so it was repeated at 9 P.M. Pulse 114 ; temperature $104^{\circ}$. Given as much nourishment as possible in the shape of raw eggs, strong beef-tea, and milk. Chloral still continued.

14th.-9 A.M. : Bowels acted freely after second black draught; had no sleep during the night, the delirium continuing without intermission. Pulse 144 ; temperature $103^{\circ}$. Ordered thirty drops of tincture of digitalis in an ounce of water every two hours. The chloral discontinued. Abdomen still tympanitic, but not particularly tender. The blush round the wound has not extended; no vomiting; takes his nourishment well. -9 P.M. : Temperature $103.4^{\circ}$; pulse 124 , not intermittent, and better in tone. Has taken four doses of digitalis. The delirium has been almost constant all day. Still sweating profusely. Ordered a draught of forty grains of chloral and forty grains of bromide.

15th. -9 A.M. : Temperature $102^{\circ}$; pulse 100 and regular. Slept at intervals during the night; is rational this morning and quiet, but much exhausted; tongue moister and slightly cleaner at edges; bowels acted freely in the night; erysipelas extended over the whole of the lower part of the abdomen, which is extremely tender; urine loaded with lithates, sp. or. 1025, and slightly albuminous. Digitalis continued every four hours; linseed poultice applied to abdomen, but pad of tincture of benzoin not removed; forty grains each of chloral and bromide given at 11 A.M. - 9 P.M. : Has slept nearly all day. Pulse 108 , regular; temperature $102^{\circ}$. To have forty grains of chloral at once.

16th.-9 A.M. : Temperature $102 \cdot 4^{\circ}$; pulse 102 ; no signs of intermission; slept nearly all night, and continues quite rational, only wandering slightly at times. Digitalis discontinued, and twenty grains of chloral given three times a day. Bowels acted freely this morning. The whole of abdomen covered by the erysipelatous redness and swelling, which has also extended to penis and scrotum, which parts are intensely red, tender, and odematous; the tympanites rather diminished. The pad of tincture of benzoin was removed. The upper edge of the wound has anited by first intention; from the lower edge, which was open, flowed a large quantity of thin flocculent pus, which was pent up between the abdominal muscles and fascia on the left side. The pins were not removed, as they seemed to create little or no irritation, but the horsehair sutures between them were taken out, so as to allow a free exit for discharge; poultices and fomentations applied over the whole part. -9 P.M. : Temperature $102^{\circ}$; pulse 99 . Not in so much pain; wound discharging freely into the poultice; bowels have acted twice during the day. Forty grains of chloral to be given at Il P.M.

17th.-9 A.M.: Temperature $101^{\circ}$; pulse 106. Slept nearly all night; pain much easier; erysipelatous redness subsiding and oedema of penis and scrotum a little less; skin moist and tongue cleaner; he is quite rational, and takes his nourishment well. Poultices continued; wound still discharging very freely; urine slightly albuminous. The chloral left off during the day, and tincture of perchloride of iron with in fusion of quassia given three times a day. - Evening: Temperature $102 \cdot 6^{\circ}$; pulse 98 . Given forty minims of nepenthe.

18th. - Morning : Slept well; pulse 92; temperature $1024^{\circ}$. Discharge still profuse. No return of delirium. Abdomen, penis, and scrotum a good deal better. Bowels acted once. -Evening: Temperature $100^{\circ} 4^{\circ}$; pulse 82 . Given forty minims of nepenthe.

19th.-Morning: Slept well. Discharge still profuse Temperature $98.4^{\circ}$; pulse 84 . Redness over abdomen and other parts subsiding rapidly.-Evening: Temperature $100.4^{\circ}$; pulse 88. Nepenthe repeated.

20th.-Morning : Temperature $100^{\circ}$; pulse 76 . Slept well. Going on favourably.-Evening: Temperature $101^{\circ}$; pulse 86. Urine still slightly albuminous.

2lst. - Passed a good night. Pulse 76 ; temperature $99^{\circ}$. Erysipelatous redness nearly all subsided. Very little dis. charge. The poultice left off, and the harelip pins removed. Wound firmly united, except for about quarter of an inch in the centre, from which there is a little thin sanious discharge. Water-dressing and carbolised tow applied.

22nd.-Temperature $99^{\circ}$. Slept well all night. Very

little discharge from the wound, which looks very well.

23rd.-Temperature and pulse normal. Lower part of abdomen desquamating. Put on meat diet.

24th.-Discharge ceased; wound quite closed. A good deal of inflammatory thickening remains in those parts of the abdominal wall to which the erysipelatous action extended. 28th.-Up, and going on favourably.

April 5th.-Discharged from the infirmary cured. Appeared at the assizes at Monmouth, and gave evidence the same day. The urine continued slightly albuminous when discharged.

\section{Mttedical Sorretris.}

\section{OBSTETRICAL SOCIETY OF LONDON.}

Extra-uterine Fotation.-Dicephalous Monster.-Bicorned Uterus and Vagina.-Myxoma of Ovaries.-Repositors and Midwifery Forceps.-Revolution of Fotal Head in passing through Contracted Pelvic Brim.

AT the meeting on June 5th (Dr. West, President, in the chair) the following gentlemen were elected Fellows of the Society :-J. D. Buncombe (Beaufort West, Cape Colony), John A. Lycett (Graiseley), John O'Neill, M.D. (Portobello), John A. Rawlings (Swansea), and David Thomson, M.D. (Luton).

The President said that the Fellows would be aware that the Society had recently acquired the valuable library of the late Dr. Blundell, but as they already possessed many of the works thus purchased, the Council thought it advisable to offer the duplicates for sale. He had therefore to announce that a list of such works, with the prices at which they were valued, would be suspended at the Society's library, and Fellows would thus be given such an opportunity as they might seldom find of acquiring valuable works on obstetrics.

Dr. HAYES exhibited the specimen from a case of Extra. uterine Fotation, of which he had given brief particulars at the last meeting of the Society. The specimen consisted of 